\title{
El proceso de gentrificación en Génova a partir de las trasformaciones urbanas de 1992
}

The process of gentrification in Genoa from the urban transformations of 1992

Profesor Francesco Gastaldi, Federico Camerin ${ }^{1}$

\section{Filiación}

Universidad IUAV, Venecia, Italia

E mail: gastaldi@iuav.it, urbancame@alice.it

Primera versión recibida en: 05 de abril, 2015

Última versión recibida en: 15 de diciembre, 2015

\section{Resumen}

Este estudio sigue algunas actividades de investigación y publicaciones relativas a las políticas urbanas en la ciudad de Génova, con especial interés en los proyectos relacionados con el centro histórico de la ciudad y el frente marítimo, así como con el papel que los grandes eventos juegan en el proceso de regeneración urbana. En este marco, el tema de la gentrificación que se investiga, es la dinámica de los nuevos residentes con mayores niveles de ingreso que se ubican en el centro histórico y el consiguiente desplazamiento de los residentes anteriores, observable a partir de los años noventa. La decisión de reubicarse en edificios degradados comenzó a verse no como una opción inevitable para las poblaciones con menos recursos económicos, sino como una solución ideal para ciertas personas con una fuerte necesidad de interacción y de representación social, atraídos por el patrimonio histórico, cultural y valores del entorno urbano, por la centralidad de la zona, y por las oportunidades de inversión.

\section{Palabras clave}

Gentrificación; Grandes eventos; Regeneración urbana; Génova

\begin{abstract}
This study follows some research activities and publications concerning urban policies in the city of Genoa, with specific interest in projects linked to the old city centre and the waterfront, and the role of great events in urban regeneration. In this framework, the topic of 'gentrification' is investigated, is the dynamic of new residents with higher income levels moving into the old city centre and displacing the previous residents, clearly visible from the second half of the 1990s. Deciding to relocate into run-down buildings started to be seen, not as an unavoidable choice for marginalized populations, but as an ideal solution for certain people with a strong need for social interaction and representation, started to be attracted by the historical, cultural and environmental values, by the centrality of the area, and by investment opportunities.
\end{abstract}

\section{Keywords \\ Gentrification; Great events; urban regeneration; Genoa}

\section{Sumario}

\footnotetext{
${ }^{1}$ Este artículo es el resultado de la investigación llevada a cabo por los dos autores. En este contexto la introducción y las conclusiones han sido desarrolladas por parte de los dos autores. Las secciones 2, 3 y 4 se atribuyen a Francesco Gastaldi y las secciones 1 y 5 a Federico Camerin.
} 


\section{Introducción}

1 Los grandes eventos y la regeneración urbana de Génova

2 El proceso de cambio social

3 La evolución del mercado inmobiliario

4 La redefinición del espacio público

5 El éxito en la gestión de proyectos de regeneración urbana en Génova y los retos de la ciudad para el futuro

\section{Conclusiones}

\section{Referencias}

\section{Introducción}

Este trabajo examina la relación entre grandes eventos (la Expo Colón de 1992, la Cumbre del G8 de 2001 y Génova Capital Europea de la Cultura en 2004), los procesos de regeneración urbana y de gentrificación, y el papel que juegan las políticas públicas en el desencadenamiento y apoyo a la transformación social y en los cambios en el uso de las viviendas, especialmente en referencia a sus implicancias en el modelo de desarrollo positivo del núcleo urbano por los recientes acontecimientos.

El escrito presenta una introducción donde se problematiza el tratamiento del concepto de gentrificación y se describen las características de la ciudad de Génova. A ésta le siguen la investigación de las transformaciones derivadas de la implementación de las políticas urbanas y la identificación del fenómeno de gentrificación en el centro histórico de la ciudad. Para su interpretación se ha realizado un análisis compuesto de un trabajo de campo, por medio de observaciones y verificaciones en terreno de las tendencias de mayor impacto entre 1992 y $2007^{2}$, así como de consulta de fuentes secundarias. Para esto se ha examinado la evolución de los datos estadísticos de las características de la población residente ${ }^{3}$, en conjunto con la realización de un estudio de campo, constituido por una serie de entrevistas a residentes del centro histórico. En el caso genovés los aspectos ligados al sector inmobiliario se han investigado a través de la información proporcionada por la "Asociación para el Estudio y la Información sobre los Mercados Inmobiliarios Locales" (en italiano Associazione per lo Studio e I'Informazione sui Mercati Immobiliari Locali, ASSIMIL, en www.assimil.org), y datos obtenidos por medio de entrevistas a algunos operadores inmobiliarios que desarrollan su actividades en el centro histórico de Génova.

A continuación se procede a interpretar las situaciones que se generaron a partir de la implementación de los procesos de transformación urbana, a identificar los beneficios que se han desencadenado, así como los retos y riesgos que se vislumbran para el barrio en un futuro inmediato. En las conclusiones del escrito, no obstante se deja en claro que la gentrificación es un fenómeno de efectos múltiples a los cuales es difícil atribuir una connotación universal

2 Los autores han elegido el período 1992-2007 por diferentes motivos: 1992 fue el año de la Expo, en 2006 la UNESCO reconoció el centro histórico de Génova como Patrimonio de la Humanidad, y en 2007 terminó el segundo período del alcalde Giuseppe Pericu (1997-2007). En seguida, la nueva administración encabezada por Marta Vincenzi fomentó nuevas y diferentes políticas, poniendo menos atención al binomio centro histórico-waterfront. Además el 2007 fue el último año antes de la crisis económica y financiera del sector público y fue el año del estallido de la burbuja inmobiliaria en los países de Europa Occidental.

3 Los datos para el análisis de los cambios sociales se han obtenido a través de la web http://statistica.comune.genova.it/pubblicazioni/archivio.php, de los censos del Ayuntamiento de Génova (2014 y 2015) y del instituto nacional de estadística de Italia, ISTAT (http://demo.istat.it/bilmens2015gen/index.html) 
(tanto positiva como negativa) (Atkinson, 2003) ${ }^{4}$, se quiere demostrar que en el centro histórico de Génova se ha desencadenado una gentrificación "suave" (Bagnasco, 1990; Piccolomini, 1993; Gaeta 2006; Annunziata, 2007; Diappi, 2009; Annunziata, 2014) y tendencialmente "positiva" (Florida, 2002).

Los grandes eventos han jugado un papel crucial en las transformaciones urbanas que se han llevado a cabo en Génova ${ }^{5}$ desde 1992, tanto por las grandes inversiones que se requirieron como por la redefinición de su imagen, basando el proceso sobre la experiencia precursora de Barcelona (Delgado, 2009; Mazzoleni, 2009). Según Roche (2000) por "grandes eventos" se entienden eventos culturales de gran escala, incluyendo eventos comerciales y deportivos, que tienen un carácter dramático, atractivos a la masa popular y de una significación internacional. Normalmente están organizados por combinaciones variables de organizaciones gubernamentales y no gubernamentales nacionales e internacionales. En Italia se ha desarrollado una amplia literatura crítica sobre los "grandes eventos" (Bobbio y Guala, 2002; Segre y Scamuzzi, 2004; Gambino, Mondini y Peano, 2005; Guala, 2007; Vitellio, 2009; Di Vita, 2010; Autores, 2015). A través de los grandes eventos, la transformación urbana, la mejora y el mantenimiento han afectado el centro histórico y el frente marítimo - en inglés waterfront - del Puerto Antiguo ${ }^{6}$, contribuyendo de manera decisiva a revertir el proceso de degradación física, económica y social que le afectaba.

Diferentes conceptualizaciones e interpretaciones de un conjunto de fenómenos, muy amplios y a veces heterogéneos, se incluyen bajo la etiqueta de la gentrificación: desde la definición precursora por Glass (1964), se ha desarrollado una vasta literatura internacional. En Italia, desde el principio de los años Noventa, se ha descrito este fenómeno como un proceso "suave" de cambio social (Bagnasco, 1990; Piccolomini, 1993; Gaeta 2006; Annunziata, 2007; Diappi, 2009; Annunziata, 2014) relacionado con las operaciones de transformación urbana, aunque no haya llevado a la expulsión masiva de la clase débil de las zonas impactadas por la mejora urbana, como se ha verificado en Inglaterra y en Estados Unidos (Bovone, Mazzette, 2005; Manzo, 2012).

Los efectos en una determinada parte de ciudad de programas con objetivos de regeneración urbana, han sido motivo de estudio desde diferentes disciplinas: entre otros efectos, las consecuencias generadas en el centro de la ciudad por la llegada de newcomers, incentivados por nuevas condiciones surgidas a raíz de la regeneración (Cameron, 1992). La gentrificación de áreas sometidas a tales programas es uno de los aspectos más controvertidos de los programas de regeneración. Según Helms (2003) las áreas que habitualmente son susceptibles

4 En cuanto este juicio, depende en primer lugar del stakeholder que se toma en consideración y además es imprescindible de la ideología de base del investigador.

5 Génova es una ciudad-puerto italiana que cuenta con 593.232 habitantes en fecha 31 de diciembre de 2014 (http://demo.istat.it/bilmens2015gen/index.html) en un área de 24.045 hectáreas. La ciudad está dividida en 25 circunscripciones y 71 barrios, llamados unità urbanistiche (figura n. 1), y es la capital de la provincia homónima y de la región de Liguria. El centro histórico de Génova, se compone por seis tres barrios llamados sestieri: Maddalena, Molo, Portoria, Pré, San Teodoro y San Vincenzo. De estos, los distritos cuyo limites actuales responden a un tema de concentración de bienes patrimoniales reconocidos como Patrimonio de la Humanidad el 13 de julio de 2006 son aquellos de Maddalena, Molo y Prè, representando de hecho el verdadero centro histórico de la ciudad, o sea la parte de origen medioeval de la ciudad, con un área de 113 hectáreas y 22.826 residentes en data 31 de diciembre de 2014 , en disminución con respeto al censo del 31 de diciembre de 2013, o sea -1,45\% (Ayuntamiento de Génova, 2015). A lo largo del artículo cuando se va a hablar de "centro histórico" se hace referencia a los sestieri de Maddalena, Molo y Prè, que también componen la circunscripción llamada "Prè-Molo-Maddalena".

6 Por el caso de Génova cuando se habla de intervenciones en el centro histórico se trata de "regeneración urbana", mientras por lo que merece al waterfront del Puerto Antiguo se habla de "reconversión portuaria". El waterfront del Puerto Antiguo es el área que va desde la Stazione Marittima (en figura 2) hasta los Almacenes de algodón, y se configuraba como una zona industrial abandonada que, a partir de la Expo de 1992, ha sido reconvertida en términos de creación de nuevos espacios para fomentar el ocio, el turismo y la cultura. En el artículo se hablará solamente del waterfront del Puerto Antiguo y no del frente marítimo de otras partes de la ciudad. 
de gentrificación son aquellas que se ubican en centros históricos, de baja densidad, con viviendas de una idiosincrasia distintiva y que habitualmente presentan espacios ajardinados o zonas verdes. A menudo son espacios fácilmente transitables, cerca del Central Business District y lejos de grandes autopistas o de polígonos de vivienda social. En los centros históricos el atractivo inherente del área convive con el deterioro propio del avance del tiempo, donde se mezclan tradiciones del pasado con culturas del presente. Además, es en estas zonas donde se observa una importante presión sobre el suelo, ya que la demanda, frecuentemente, es mucho mayor que a la oferta. Algunos autores como Harvey (1985) destacan la contribución de los promotores inmobiliarios y los propietarios de vivienda de alquiler a la aceleración de los procesos de gentrificación en algunos barrios.

En definitiva, las características de un barrio, que a menudo se identifica en el centro histórico, así como la existencia de un determinado sistema de vivienda, determinan el potencial que éste puede tener para cambiar su estructura económica, social y urbanística, lo que finalmente puede traducirse en un proceso de gentrificación. El debate que crea esta dinámica genera controversia: por un lado, se considera a la gentrificación "negativa" como fuerza centrífuga de aquellos con menos recursos y mayor vulnerabilidad en el barrio provocando así un desplazamiento involuntario, una mayor segregación y un aumento de la polarización social (Slater 2006; Lees, 2008). Por otro, la hipótesis tradicional acerca de una gentrificación "positiva" que determina una mejora incuestionable del barrio bajo criterios de sostenibilidad y menor segregación (Florida, 2002) basada en la hipótesis del filtrado se viene generalizando en buena parte de las intervenciones en los países desarrollados. Aun así, Lees (2008) afirma que existe poca evidencia empírica de los efectos beneficiosos en los barrios de la llegada de gentrifiers.

Teniendo en cuenta las especificidades territoriales y socio-culturales del contexto italiano y el "redescubrimiento" de los antiguos centros de las ciudades, así como de sus valores culturales, y el nuevo protagonismo en muchas ciudades europeas de los barrios emergentes, la perspectiva de análisis que los autores proponen está relacionada con teorías voluntaristas (Atkinson, Bridge, 2005; Piccolomi, 1993). Según este enfoque la gentrificación es el resultado de decisiones relacionadas con los valores cambiantes, el consumo individual de la población de mayores recursos económicos y culturales, los estilos de vida, los procesos de regeneración urbana7 y las nuevas dinámicas urbanas, y no por la diferencia entre la riqueza de las personas (Smith N., 1987), no obstante no se puede estar totalmente en desacuerdo con esta teoría.

Así como en otras ciudades italianas - en particular Milán, Roma y Turín (Semi, 2015) - el fenómeno de gentrificación en Génova se ha caracterizado por una dinámica demográfica, económica y de desarrollo de infraestructura similar, aunque a partir de condiciones muy diferentes. A menudo se trata de dinámicas interrelacionadas, como lo demuestra, por ejemplo, la historia de los "vacíos urbanos" producidos por la desindustrialización, donde se mezclan las dinámicas urbanísticas (las vastas zonas de la ciudad industrial abandonadas), con aquellas económicas, sociales y demográficas (la pérdida de población, su progresivo envejecimiento y

7 La "regeneración urbana" es un tipo de política urbana propia del último cuarto del siglo XX, o sea el conjunto de aquellas actuaciones destinadas a la recuperación de la actividad económica, la integración social y el medio físico y ambiental de un territorio (Couch, Fraser y Percy, 2003; Castrillo, Matesanz, Sevilla y Domingo Sánchez, 2014). La regeneración urbana se refiere a la gestión y planificación de áreas urbanas ya existentes, más que a la planificación y desarrollo de nuevas áreas urbanas (Roberts y Sykes, 2000; Instituto Universitario de Urbanística de la Universidad de Valladolid, 2010; Nel·lo, 2010). La regeneración urbana se preocupa del re-crecimiento de la actividad económica, el restablecimiento de la función social, de la inclusión social y del restablecimiento de la cualidad de equilibrio ecológico. En el centro histórico de Génova se ha observado un fenomeno de regeneración urbana que no ha implementado actuaciones de demolición y reconstrucción (salvo raras excepciones, como la del barrrio Famagosta) sino de reestructuración del entorno urbano preexistente, centrandose sobre todo en el cambio de las condiciones socioeconómicas del barrio. 
los cambios en los mercados laborales locales). Las políticas territoriales han adoptado diferentes tipologías de acción para contrastar este fenómeno, frecuentemente con políticas e instrumentos que se han superpuesto y han variado entre la centralización y la descentralización, intensificado la peculiaridad italiana en comparación con otros países europeos (Annunziata, 2014). Además la gentrificación italiana es observable en la intersección de la forma en que los gobiernos locales han respondido a los cambios mencionados anteriormente y la tendencia de distintas clases sociales italianas a transformarse en propietarios de la casa (Barbagli, Pisati, 2012).

\section{Los grandes eventos y la regeneración urbana de Génova}

Hasta la década de 1990, Génova se caracterizaba por un sistema urbano crecido sobre una matriz medieval, que evolucionó a través de la realización y la renovación de edificios, con algunas grandes intervenciones estructurales, tales como la apertura de algunas calles caracterizadas por la presencia de edificios del siglo XVI y XVIII. El proceso de transformación urbana, recalificación y mantenimiento, que vio como protagonistas el centro histórico y el watefront del Porto Antico (el Puerto Antiguo) ${ }^{8}$, se inició en 1992, año de la Expo Colón para celebrar el quinto centenario del descubrimiento de América, y más tarde fue confirmado y desarrollado con la Cumbre del G8 celebrada en julio de 2001 y el evento Génova capital Europea de la Cultura en 2004.

Estos eventos contribuyeron positivamente al inicio de un proceso para revertir la tendencia de deterioro físico, económico y social que estaba presente en muchas partes de la zona central de la ciudad, por medio de la creación de un nuevo waterfront ${ }^{9}$ que conectaba la histórica dársena del puerto y el núcleo antiguo de la ciudad (Seassaro, 2001). En el proceso general de transformación urbana de Génova, han sido fundamentales la identidad histórica y cultural específica de la ciudad, la ausencia de un conflicto significativo o permanente entre los distintos agentes interesados en la transformación social, el proceso difuso de renovación de las viviendas, la apertura de nuevos locales "de moda" y, en general, la evolución del tejido comercial funcional a los nuevos usuarios, así como la presencia de una demanda atenta a las componentes artísticas de la oferta lúdica, cultural y comercial, contribuyendo a desarrollar sustanciales cambios en el paisaje urbano del centro histórico (Smith, 2001).

Al mismo tiempo se sumó a esta estrategia de regeneración la realización de otras obras públicas, algunas de las cuales, como la restauración del complejo de museos de San Agustín y la apertura del teatro Tosse, han tenido lugar en el centro histórico, y otras, como el nuevo

8 El Puerto Antiguo es una zona rica de elementos de identidad apartenentes al antiguo pasado industrial. Génova es una ciudad históricamente legada al mar y a las actividades puertuarias donde hay muchos edificios representativos de esa história, como los Almacenes de algodón, los Muelles, etc. Estos "patrimonios" portuales representan unos elementos identitarios que en la transformación llevada a cabo para la Expo de 1992 no se han derribado, sino se han reconvertido porque son elementos patrimoniales e identitarios de la memoria de la ciudad. Por aprofundir las cuestiones relativa a los conceptos de patrimonio e identidad se remite a Choay (2015).

9 Por lo que merece el waterfront del Puerto Antiguo de Génova, así como en otras ciudades-puertos en el mundo, se ha observado un proceso de transformación de las zonas portuarias obsoletas, definido como "reconversión portuaria" (Fagense, 1995; Bruttomesso, 1999). Las intervenciones desarrolladas han generado una apertura de la ciudad al mar, construyendo nuevas áreas de centralidad urbana que apartan la actividad puramente industrial portuaria y dan cabida a nuevas actividades fundamentalmente de ocio, comerciales, terciarias, turísticas y culturales. La definición del término "reconversión" abarca un campo complejo de actuaciones de cambio de uso, reutilización, modificación y transformación bajo el prisma de los diversos intereses que se concentran en el límite puerto/ciudad, en una zona que es de conflicto y competencia tanto como de cooperación. Por ello, los conceptos de revitalización, reutilización y desarrollo se emplean a menudo como sinónimos de reconversión (Shubert, 2004). En particular, en Génova la reconversión del waterfront se ha basado en la reutilización de edificios y conjuntos arquitectonicos danados y/o abandonados, en muchos casos de gran significacion historica y cultural, símbolos de las actividades portuales. 


\section{URBANISMO}

centro cultural de Palazzo Ducale y el Teatro Carlo Felice, se han desarrollado en zonas cercanas al centro.

Sustancialmente el binomio centro histórico-waterfront ha capturado las decisiones de política urbana más importantes durante la década de 1990 y los primeros años de la década de 2000, para atraer un mayor interés por parte de la opinión pública y más financiamiento. En consecuencia, el interés en esta área ha crecido progresivamente hasta llegar a ser el lugar más representativo de toda la ciudad (Guala, 2005).

Las intervenciones relacionadas con grandes eventos - renovación y mantenimiento urbano, recuperación de espacios públicos, la restauración de fachadas de edificios y lugares de valor arquitectónico - se han llevado a cabo en conjunto con la mejora de la red de carreteras, la consolidación de una política de peatonalización, la regularización de los flujos de tráfico en la manera de dar nuevos roles y un nuevo aspecto a las características tradicionales de la ciudad - Plaza De Ferrari, Vía Garibaldi con su museo en Palacio Rosso - y de nuevos ejes o centros urbanos - Vía San Lorenzo, el área del Expo y las fachadas de Sottoripa, Vía Cairoli y Vía Balbi.

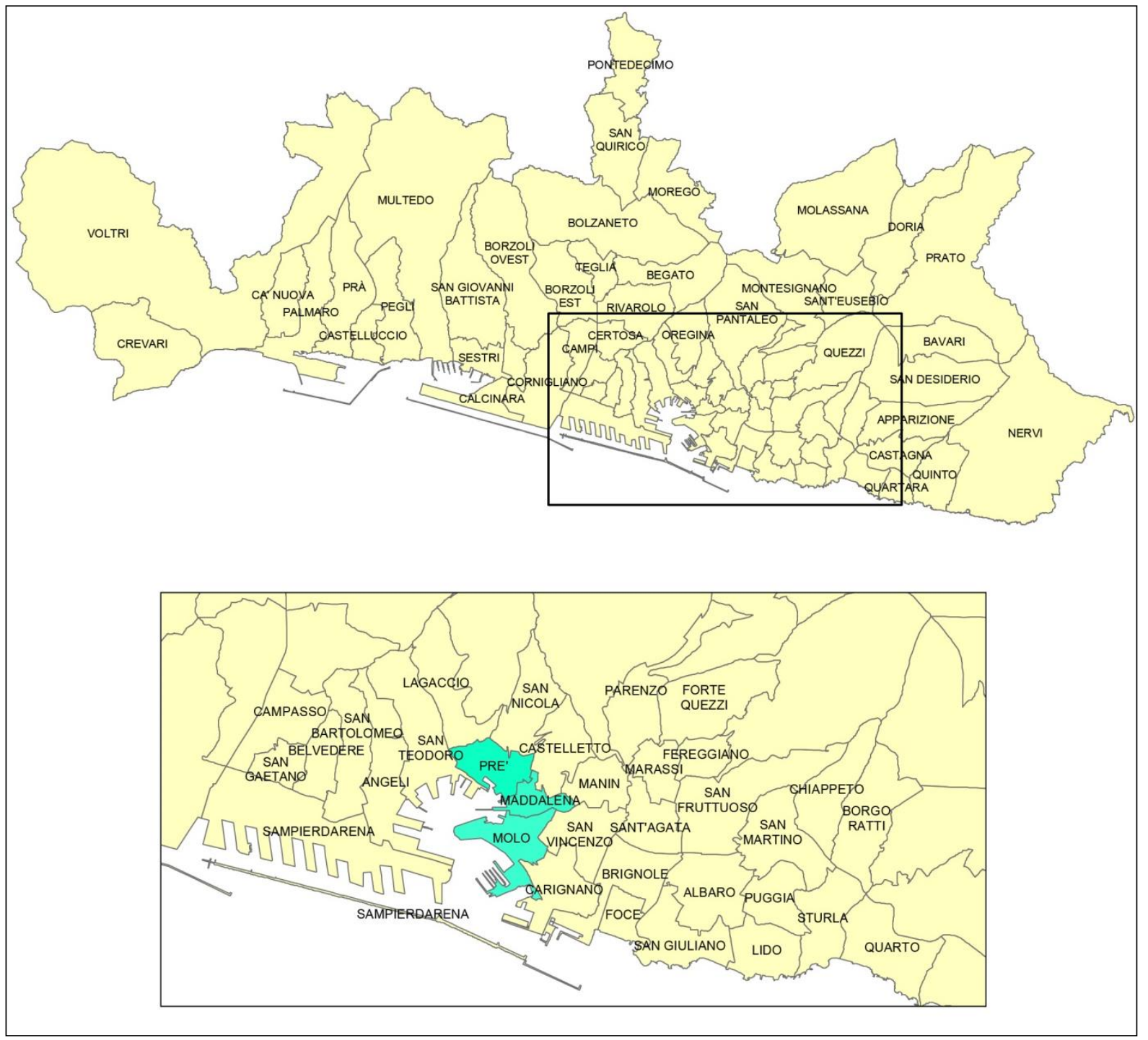


Fig. 1: mapa de las unità urbanistiche (barrios) de Génova, que desde 1980 el Ayuntamiento de Génova divide el municipio, basados en las realidades históricas y urbanísticas de la ciudad. En azul se han marcado aquellas que componen el centro histórico.

Fuente: elaboración por Federico Camerin.

Conjuntamente con las intervenciones públicas relacionadas con estos grandes eventos, la administración pública estimuló el proceso de transformación urbana mediante la atracción de otras formas de inversiones públicas y privadas que fueron externas al presupuesto ordinario: los programas de financiamiento comunitario para la regeneración urbana de la UE, como el Programa Urban II, los programas italianos, nacionales y regionales y las partneship públicoprivadas, todos han actuado a favor de la regeneración de la ciudad. Estos programas crearon una sinergia entre la recalificación física de los edificios y espacios públicos - importantes como Plaza Sarzano, Plaza delle Erbe y la Subida del Prione - y acciones de regeneración socioeconómica.

El acuario de Génova realizado por el arquitecto Renzo Piano en 1992 para la Expo Colón, el segundo más grande en Europa después del de Valencia, en más de veinte años se ha convertido en la principal fuerza impulsora en la redefinición del waterfront en términos de turismo y ocio, con más de 1,2 millones de visitantes al año. El mismo arquitecto genovés realizó, con motivo de la cumbre del G8 de 2001, una estructura que se suma a las exposiciones del acuario, llamada "Bolla". La zona de la Expo es ahora una atracción urbana muy importante y bien conectada, que también contribuye a desplazar los turistas a otras áreas del centro de la ciudad.

En la Dársena, además, del traslado de la Facultad de Economía y Comercio al barrio de Cembalo, se han creado también nuevas funciones residenciales y comerciales, incluida la ubicación de la Alta Escuela Náutica. A esto se suman la demolición del barrio Famagosta, la reconstrucción parcial del edificio Bacinetto, que alberga el nuevo Museo del Mar y de la Navegación en Galata, realizado como parte del evento cultural de 2004, así como la promoción de obras de rehabilitación en los barrios de Caffa y Metellino.

En el caso de la Dársena, las intervenciones fueron parte de una estrategia para recuperar las áreas abandonadas hace años en el puerto. Esta operación se basó sólidamente en la introducción de funciones que integraron el turismo con lugares de interés cultural y la salvaguardia de la memoria del entorno portuario.

Un papel importante en el complejo proceso de regeneración urbana y valorización activa del waterfront-centro histórico fue interpretado por la Universidad de Génova que echó raíces en el corazón de la ciudad durante los primeros años de 1990, instalando en la Dársena algunas sedes, como la Facultad de Ciencias Económicas y la Facultad de Arquitectura, además de fomentar la instalación y el desarrollo de las otras estructuras ya existentes. Como parte de un programa de expansión, la Facultad de Letras y Filosofía adquirió un nuevo edificio, contribuyendo a un rediseño general cerca de Vía di Pre, una de las zonas más degradadas del barrio. Además esta área se ha transformado en zona de alojamiento para estudiantes: de hecho se han construido un centenar de pequeñas residencias. Todas estas intervenciones, especialmente las obras por la nueva ordenación de la red de carreteras y en los edificios históricos como Palacio dei Rolli, han llevado a la UNESCO a reconocer el centro histórico de Génova, como Patrimonio de la Humanidad el 13 de julio de 2006.

Un total de 650 millones de euros se gastaron entre 1993 y 2005, aproximadamente un 75\% de los cuales fue puesto a disposición por parte de organismos públicos diferentes del municipio de Génova. 


\section{URBANISMO}

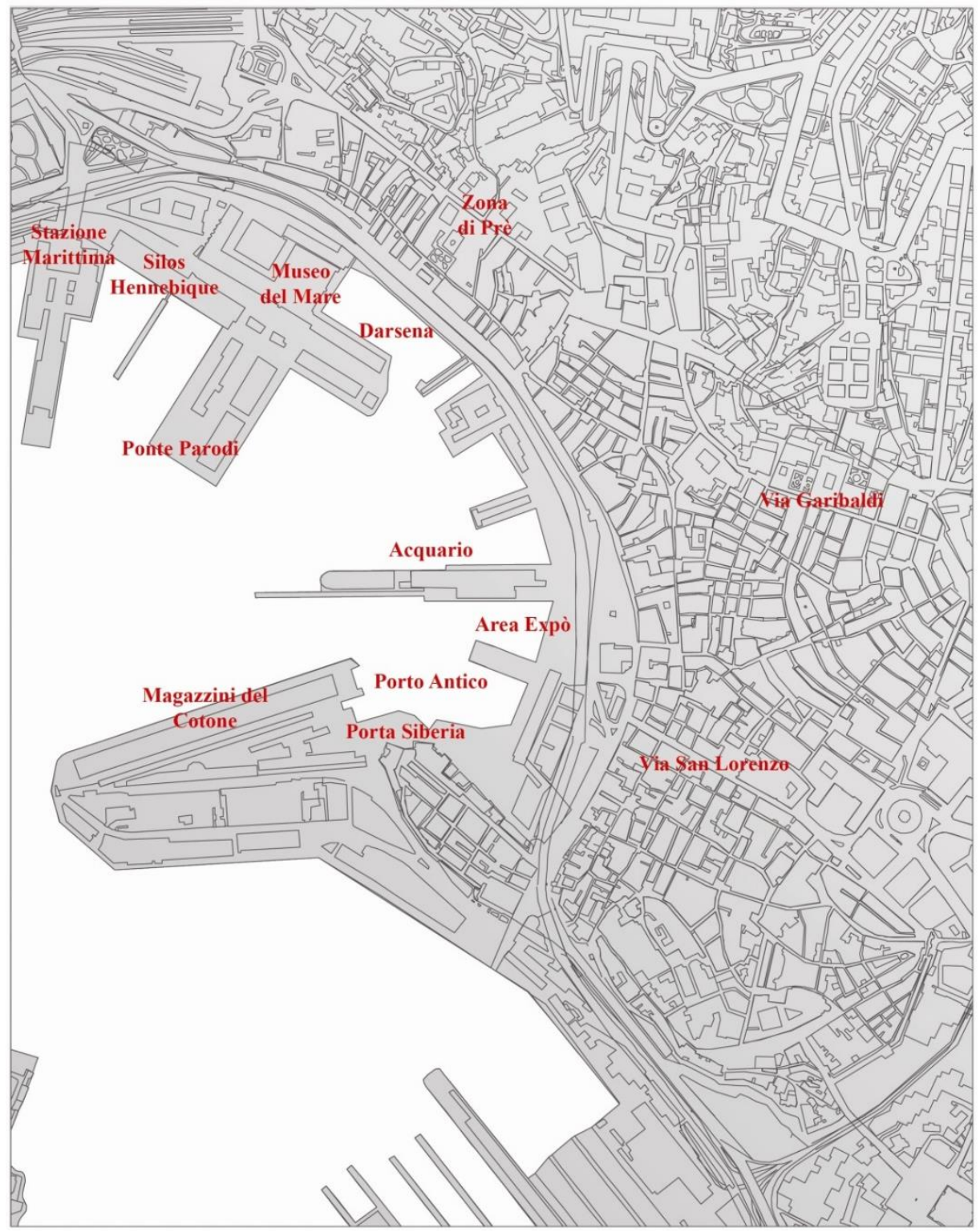

Fig. 2: planimetría de la zona del Puerto Antiguo.

Fuente: elaboración por Francesco Gastaldi.

Todas estas decisiones y acciones enmarcadas en la política pública han desencadenado procesos duraderos de mejora de la calidad urbana, favoreciendo el desarrollo de ulteriores proyectos, por medio de la incorporación de operadores privados en el marco normativo. A su vez, esto ha alimentado un aumento en el valor de algunas áreas ${ }^{10}$, ha cambiado la imagen de la ciudad, ha llevado a los residentes de Génova a redescubrir su propia ciudad, y ha contribuido al incremento gradual del turismo. Los primeros signos del inicio del proceso de gentrificación se observaron en la primera mitad de la década de 1990. No obstante en distintas ciudades europeas las administraciones públicas facilitaron el hecho de que la

10 Eso ha implicado, en las zonas más interesadas por las obras de regeneración urbana, un aumento de valor por metro cuadrado alrededor del $210 \%$ en 10 años: en 1995 el valor estaba entre 1.000 y 1.5000 euros por metro cuadrado y en 2005 entre 4-5.000 euros por metro cuadrado (Semi, 2015). 
población con mayores recursos pudiera desplazarse al centro produciendo gentrificación, es importante tener en cuenta cómo en las ciudades italianas y en específico en Génova eso no se ha producido ni por las decisiones sobre la planificación urbana, ni como resultado de una estrategia puesta en práctica por las grandes operaciones de propiedad. De hecho es consecuencia de una serie de acciones individuales no predecibles, enmarcadas en un marco normativo que detonó mayores transformaciones a través de una adaptación del parque de residencial, del tejido social y de la situación económica. Mientras tanto, durante los últimos años Génova ha optado progresivamente por limitar otras formas de expansión en las zonas de ladera que rodean la ciudad, dirigiendo la atención y los recursos invertidos a la parte más antigua de la ciudad.

En el centro histórico de Génova, respecto a una tendencia consolidada a lo largo de los años como resultado de siglos de movimientos de las clases altas hacia las zonas periféricas, en una dinámica de expansión continua de la ciudad -, se ha creado un punto de discontinuidad, el regreso de la clase media y alta a la parte central de la ciudad. El fenómeno implica un cambio de actitudes por parte de los residentes tradicionales y adquiere nuevos significados: la imagen de la ciudad antigua ya no está ligado al estatismo, la decadencia y el abandono, sino por el contrario, a un estilo de vida dinámico, caracterizado por un renovado sentido de pertenencia e identificación con el corazón de la ciudad.

\section{El proceso de cambio social}

A final de la década de 1980 la situación del centro histórico de Génova se caracterizaba por el deterioro que afectaba tanto al parque residencial como al medio ambiente urbano, así como los conflictos sociales que dieron origen a una imagen del área cada vez más asociada a la decadencia y criminalidad (Leone, 2010; Briata, 2014). La reciente afluencia de inmigrantes de los países no miembros de la UE complicó drásticamente la situación, y creó alarma social: en la opinión común el centro histórico fue considerado un lugar peligroso (Arvati, 2004; Petrillo, 2004). Los habitantes tradicionales del centro histórico se habían desplazado en general a otras áreas y, como consecuencia, los sectores desfavorecidos de la población, sobre todo los extranjeros (Martinotti, 1993; Nuvolati, 2002), se relocalizaron en esa parte histórica de la ciudad, a menudo una solución temporal inadecuada, en un marco de fenómenos que llevó a un declive acumulado del centro histórico.

El abandono de los edificios de viviendas y varios espacios públicos en las últimas décadas, el problema de la higiene y la limpieza asociada con la disposición de residuos, y la prostitución en los distritos rojos tenían una influencia negativa en esta situación. Por encima de todo, la concentración de inmigrantes trajo problemas y conflictos muy amargos entre los antiguos y nuevos residentes.

En la nueva comunidad de inmigrantes, el número de ilegales, muchos chantajeados por organizaciones criminales, era alto. Esto creó un aumento de la tensión social en la zona y un creciente sentimiento de impaciencia e intolerancia entre los residentes más antiguos (Petrillo, 2004).

En el mismo período, se formó un movimiento de residentes quienes a pesar de su composición muy diversa - en relación a orientaciones políticas, actitudes y modelos culturales (Guala, 1993) - compartían la misma voluntad de devolver la seguridad y la dignidad de la vida cotidiana en el centro histórico, aunque de diferentes maneras. En algunos casos, los comités ciudadanos promueven movilizaciones contra los inmigrantes, que a veces acaban en incidentes. En otros casos, las asociaciones de vecinos han actuado en formas menos extremas y han sido mucho más proactivas. 
El fenómeno de gentrificación comenzó en el área de San Donato, Plaza Sarzano y la subida Pollaiuoli a principios de 1990, y el evento que detonó el proceso fue el desplazamiento de la Facultad de Arquitectura. Esta relocalización, junto con otras iniciativas, afectó la zona mediante la creación de nuevos flujos peatonales, eliminando los sectores débiles y marginados de la población, al tiempo que mejoró la oferta comercial - con la instalación de nuevos bares, papelerías y bookshops - y el desarrollo de alojamiento para estudiantes. Los estudiantes han sido capaces de tomar ventaja de las rentas bajas, desencadenando así un proceso espontáneo de studentification (Smith D., 2005; Semi, 2015) por la renovación del parque de viviendas, contribuyendo a cambiar las dinámicas de los precios, incluso a veces reduciendo la disponibilidad de viviendas sociales para familias. Por ejemplo, a mediados de los años Noventa, el Instituto Regional para la gestión de la vivienda pública y del patrimonio público, junto con la Agencia Regional para los Servicios Escolares y Universitarios adquirió algunos edificios en la zona de vía Gramsci para convertirlos en más de un centenar de alojamientos para estudiantes.

En cuanto a los inmigrantes extracomunitarios residentes, a partir de la segunda mitad de los años Noventa se produjo una dispersión territorial en diversas partes de la ciudad. En particular se observan dos fenómenos: uno de redistribución de una parte de la población extranjera del centro histórico a otros barrios y el segundo que los extranjeros recién llegados en Génova no deciden localizarse en el centro histórico, sino que eligen como primer asentamiento otros barrios de la ciudad. Estos dos fenómenos, que se producen incluso para los efectos de la gentrificación, no se pueden considerar "negativos" para el centro histórico, porque uno de los principales problemas fue la gran concentración de inmigrantes que ha llevado a diversos conflictos, ya mencionados anteriormente (Torti, 1992; Rocca, 1997; Queirolo Palmas, Torre, 2005; Ambrosini, Torre, 2015).

El progresivo emplazamiento de nuevos grupos de población a partir de principios de 1990 ha dado lugar a una redefinición distribuida de forma desigual: la renovación selectiva comenzó en áreas bien definidas y cuando se completó se extendió hacia el interior, coincidiendo con las zonas más degradadas. Una vez activado, el fenómeno de gentrificación tiende a ser fomentado y fortalecido de manera espontánea: la habitabilidad de la zona mejora, el uso de los talleres comerciales sube, el sentido de descuido y abandono disminuye, y la gente se siente más segura.

Nuevos residentes con menos poder adquisitivo se beneficiaron de las construcciones tugurizadas, que también tenían la ventaja de una ubicación favorable y baricéntrica en el espacio urbano que garantizaba desplazamientos más cortos, y la posibilidad de compartir las redes de profesionales y los círculos de amigos: estudiantes - inicialmente por la Facultad de Arquitectura y luego seguido por otras -, solteros y parejas con bajos ingresos, profesionales creativos, artistas, jóvenes arquitectos, emprendedores culturales y profesionales innovadores, que a veces trabajan en casa. Los diversos grupos se han movido hacia el centro histórico, atraídos por factores como su diversidad cultural, su tradición histórico-artística, y la presencia de categorías sociales que forman unas redes de relaciones interpersonales particularmente animadas. Gentrificadores que son dueños de empresas o que trabajan en varias profesiones eligen el centro histórico para aprovecharse de la estrecha relación espacial con el centro urbano $^{11}$ y porque lo consideran un buen "escaparate" que se devuelve en términos de prestigio e imagen.

11 Hasta la segunda mitad del siglo XIX, el centro urbano, entendido como "central business district" coincidía con el centro histórico, pero con el desarrollo del proceso de industrialización el centro urbano y las funciones que en eso se desarrollaban se desplazó hacia las nuevas urbanizaciones ubicadas en las colinas alrededor de la ciudad. 
El centro histórico se ha convertido en un ámbito privilegiado de forma flexible, atípico, autónomo e independiente, apto para los sectores de servicios terciarios, la cultura y la información, donde las micro-comunidades de profesionales - por ejemplo arquitectos, fotógrafos, trabajadores de teatro - y las micro-comunidades sociales, comparten estilos de vida similares

Al final de la primera década de 2000, se ha registrado un marcado incremento en el fenómeno de la soltería - el 48 por ciento de los hogares están compuestos por una sola persona, cifra que va en aumento (Semi, 2015), con personas que subrayan esta exigencia con el compromiso de una profesión estresante y la adopción de un estilo de vida muy simbólico y afectivo. Hay muchos casos de mujeres jóvenes y profesionales altamente educadas con buenos ingresos que desean posponer la formación de una familia mientras, por el contrario, casi no hay familias jóvenes y madres solteras.

Además de los cambios en el estilo de vida y en el uso de las viviendas, a principios del siglo XXI la demanda de viviendas en la parte oriental del centro histórico era muy alta y los precios de compra y de alquiler estaban en fuerte crecimiento ${ }^{12}$. Sin embargo eso ha llevado al desplazamiento a otros sectores de la ciudad de algunos de los habitantes "tradicionales", sobre todo extranjeros, y de la clase más pobre, que era incapaz de asumir el coste de la reestructuración y de los alquileres. No hay dudas que las políticas de regeneración urbana han tenido un efecto positivo en la mejora de las condiciones de vida de algunas zonas de Génova que un perfil de población - los residentes tradicionales - no logra financiar, pero han contribuido a fomentar algunos problemas de orden social (Briata 2014).

Las intervenciones urbanas y los incrementos en los precios de compra y alquiler han facilitado el desplazamiento de los inmigrantes y los grupos económicamente desfavorecidos - los extranjeros, pero no sólo ellos - a otras áreas en degradación de la ciudad, como CorniglianoSampierdarena u Oregina-Lagaccio. Entre 1992 y 2007 estas poblaciones se dirigen principalmente desde el centro histórico hacia las áreas más débiles y marginales de la ciudad, o sea Sampierdarena, Oregina-Legaccio y Castelletto. Además la población residente de toda la zona la circunscripción Pre-Molo-Maddalena disminuía de $-11,5 \%$ en la década intercensal 1991-2001 del ISTAT, o sea pasó de 21.993 en 1991 a 19.453 en 2001, pero se mantuvo en línea con el descenso medio de todo el municipio, -10,1\% - mientras que en décadas anteriores el porcentaje fue mayor. Como se mencionó antes, continuó el proceso de fragmentación de la familia, con una media de 1,70 componentes por familia respeto al 2,08 del resto de la ciudad.

En el centro histórico hubo un cambio social doble: en algunas áreas se han manifestado claros procesos de llegada de nuevos residentes - a menudo gentrifiers - y la regeneración urbana con el apoyo de las políticas públicas, mientras en otras zonas han aumentado los fenómenos de malestar social. La dispersión urbana ha tenido como efecto parcial el debilitamiento de las redes relacionales y de la solidaridad de la comunidad extranjera en el centro histórico que se habían desarrollado en la segunda parte del siglo XX (Torti, 1992; Bobbio, 2003; Erminio, 2006).

En el proceso de cambio social general se debe destacar el papel que han tenido los asentamientos universitarios en la redefinición de la identidad urbana contemporánea. Y eso está sin duda relacionado con el proceso de ampliación de las oportunidades de acceso a la educación universitaria y a la expansión de las economías del conocimiento. Pero también se puede considerar la "Universidad" como sujeto que, junto con otras entidades como museos,

12 Según la Associazione per lo Studio e I'Informazione sui Mercati Immobiliari Locali entre 1991 y 2006 en la circunscripción Pre-Molo-Maddalena el valor por cada metro cuadrado de edificios residenciales ha pasado de 810 euros por metro cuadrado a 1.600 euros por metro cuadrado, por un aumento del $97,53 \%$. 
teatros, centros de exposiciones, clubes deportivos, sindicatos locales, pequeños comerciantes, empresarios y profesionales, trabajan para la mejora de la calidad urbana (Logan, Molotch, 1987). De hecho las universidades se presentan como actores protagonistas del sector inmobiliario y económico que emplean a miles de trabajadores y caracterizan las economías locales a través de varias acciones. Trasladar una universidad significa no sólo aumentar el prestigio de un territorio, sino también desplazar comercios y servicios necesarios para la actividad residencial como supermercados y plazas. Si junto con las oficinas administrativas y la infraestructura académica, también se crean o trasladan las residencias universitarias, el efecto será sobre las poblaciones de tarde y noche en general, así como el mercado inmobiliario (que ya ha tenido un impacto por los alquileres privados para estudiantes).

En todos los efectos positivos que la regeneración y el cambio de la tipología de residentes del centro histórico ha generado, surge, sin embargo, un elemento para la reflexión, representado por el desplazamiento de los antiguos habitantes y de los sectores más pobres. De hecho a consecuencia, directa o indirecta, de algunos programas de mejora del barrio, en particular de reconstrucción de viviendas, fachadas y áreas comunes de los edificios, algunos de los habitantes tradicionales no pudieron asumir el coste reestructuración y de los alquileres y se movieron a otras áreas degradadas de la ciudad. En otros casos, algunos pioneros, después de un período de pruebas y experimentación de la vida en el centro histórico, decidieron moverse, también afectados por el aumento de los valores inmobiliarios, a veces por cuestiones de familia o la intolerancia del ruido debido a la movida nocturna.

\section{La evolución del mercado inmobiliario}

Los efectos del proceso de transformación del centro histórico se pueden observar en el cambio de los valores inmobiliarios entre la mitad de los años noventa y el final de la década de 2000.

Según los datos proporcionados por los agentes inmobiliarios que operan en el centro histórico, los alquileres de apartamentos de aproximadamente 60 metros cuadrados en esta área incluyendo la planta baja, donde menos luz penetra - fluctúan entre $600 €$ y $900 €$ cada mes, con los alquileres que incrementan en las habitaciones con particulares características - que presentan una planta superior con más luz solar, si se encuentran en un edificio prestigioso, con vista del Puerto Antiguo, una iluminación específica y también un aspecto soleado. En la zona más deteriorada, en vía di Pre, los precios de las propiedades son todavía muy asequibles: como ejemplo, una propiedad para restaurar requiere de una inversión entre $800 €$ y $1000 €$ por metro cuadrado para su rehabilitación. Esto eleva el precio de venta hasta los $1.800 €$, mientras en 1995 el coste era entre $500 €$ y $700 €$.

El 2005 (Semi, 2015) fue un año de auge, mientras que a partir de 2007 ha empezado una lenta pero constante ralentización, en términos de número de intercambios, y un ligero descenso de los precios. De hecho valores más altos respecto a aquellos de vía San Lorenzo no faltan: en zonas tranquilas para viviendas individuales en las plantas superiores en edificios de prestigio recientemente restaurados con vistas sobre los tejados, los precios incluso pueden llegar a $7.000 €$ y $8.000 €$ por metro cuadrado. 


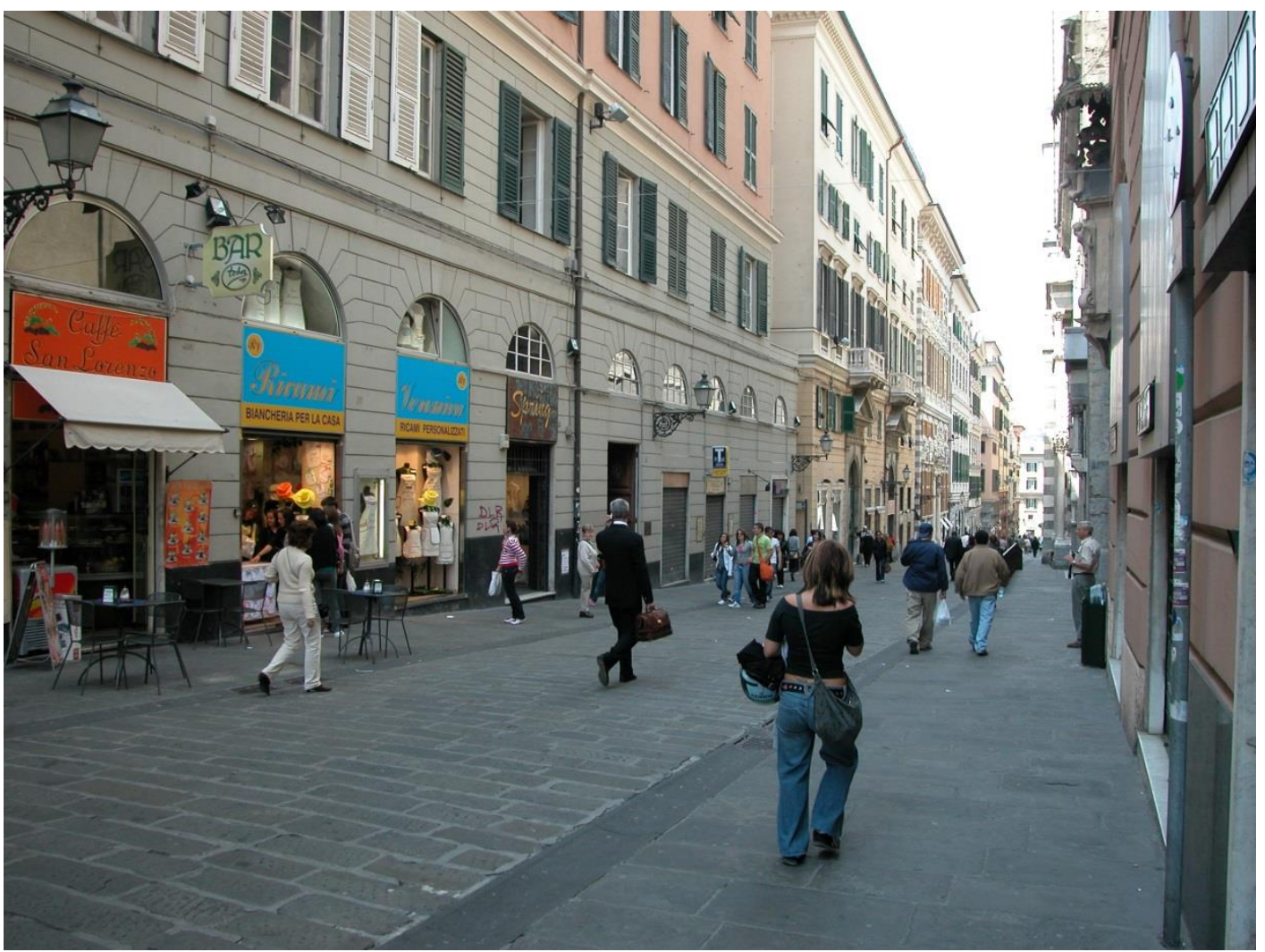

Fig. 3: vía San Lorenzo, una de las calles principales del centro histórico.

Fuente: fotografía por Francesco Gastaldi.

De acuerdo con la tendencia observada entre 1992 y 2007, el grupo que quiere vivir en el centro histórico se compone en gran parte de personas de 20 a 45 años, sean solteros 0 jóvenes parejas. El tipo de alojamientos más buscados, que se compran y se venden, pertenece a los edificios que se construyeron hace 50 y 70 años, preferentemente propiedades para restaurar, también por el deseo de personalizar el hogar.

Debido a la altura de los edificios y los estrechos callejones medievales, los apartamentos en las plantas superiores resultan los más demandados, sobre todo viviendas con un balcón o las que dan a una calle más ancha o una pequeña plaza. Hay una cierta mezcla de clases sociales que viven juntas en el mismo edificio en el centro histórico, tal de garantizar una fuerte interacción social, sea porque la dosis de luz solar recibida difiere - los edificios son principalmente más de cuatro pisos de altura, con considerables diferencias en la ventilación y la luz del día entre pisos superior e inferiores -, o porque los diferentes puntos de vista de las ventanas dan a las plazas o a las calles principales en lugar de callejones descuidados y menos frecuentados. Si los agentes inmobiliarios encuentran el parque de viviendas residenciales más deteriorado, pues no se vende, y también hoy en día la propiedad se transfiere a través de redes informales.

El centro histórico, sin embargo, es una zona afectada por una transformación arquitectónica bastante homogénea, acentuada por las zonas fronteras entre el centro histórico y el resto del centro de la ciudad, o zonas adyacentes a aquellas con fuerte polaridad urbana - a menudo coincidiendo con el más amplio tejido residencial realizado después de los daños y la destrucción de los bombardeos durante la Segunda Guerra Mundial. 
En consecuencia, los residentes con mejor situación económica del centro histórico viven en los pisos superiores de las más prestigiosas viviendas residenciales, en edificios donde vivían los aristócratas o en áticos bien iluminados. En cuanto a las instalaciones en el apartamento, excepto los casos extremos de edificios construidos en los años cincuenta y sesenta en que no hay agua corriente, ni baño o ducha, el elemento más importante es el ascensor. Esto tiene un efecto muy selectivo sobre el valor de las fincas más apetecibles que, como ya se ha explicado anteriormente, se encuentran en la parte superior de un edificio. El mantenimiento de los elementos comunes del edificio, especialmente la entrada, el pasillo y la puerta de entrada principal, constituye un factor determinante en el valor de las propiedades inmobiliarias. De hecho, de acuerdo a muchos compradores potenciales, esto es un indicador importante del carácter social del edificio y de la zona.

El centro histórico contiene viviendas asequibles en un tejido urbano de prestigio con la comodidad de estar en el centro de la ciudad, en las proximidades de las principales arterias a través del centro de la ciudad, con buen acceso a los servicios y el transporte público, un viaje al trabajo que no necesita un coche, y la oportunidad de ir de compras en una red comercial tradicional pero rica, incluso si carece de grandes centros comerciales o grandes almacenes (Semi, 2015).

Por los efectos de la transformación urbana, en Génova hubo una primera fase de renovación en el centro histórico durante el período 1994-2003, y luego una segunda fase de "estancamiento" si no de recesión entre 2004 y 2007, que continúa en la actualidad. Los indicadores de este fenómeno son la oferta superior a la demanda y la inseguridad percibida, debido al problema de la micro-criminalidad - sólo a final de 2014 , después de una década de crisis en el mercado inmobiliario, se registra un aumento en los intercambios, debido sobre todo a un fuerte descenso de los precios (Osservatorio Mercato Immobiliare e Servizi Estimativi, 2015).

Lo que ahora se ha convertido en una brecha estructural sigue existiendo entre la oferta de gran prestigio vivienda y la demanda de vivienda de bajo costo de 70 a 100 metros cuadrados que se pueden personalizar, sin tener en cuenta la ubicación. La preferencia ha tendido a cambiar a zonas tradicionalmente menos "de moda" en el oeste - que corresponde al área más allá de Dársena entre vía Cairoli y vía Lomellini, mientras que la demanda por vía Gramsci caracterizada por 15 años por varias obras de construcción - no despegó, probablemente a causa de la afluencia del tránsito, la presencia de la autopista elevada, y el área detrás vía di Prè, que todavía hoy se encuentra en un estado de degradación.

Al mismo tiempo, se ha producido una explosión en el mercado de alquiler para estudiantes, y existe una tendencia cada vez mayor para la compra por extranjeros que han echado raíces en la ciudad, no obstante ambos tipos de acceso al mercado de la vivienda suele ocurrir a través de redes informales y sólo en raras ocasiones a través de agentes inmobiliarios.

\section{La redefinición del espacio público}

En las décadas de 1990 y de 2000 las intervenciones que han afectado al centro histórico, han tenido un impacto significativo y han redefinido muchas de sus características. Los signos son evidentes, sobre todo físicos. Las fachadas de los edificios han sido restauradas por iniciativas públicas y privadas, las transformaciones han tenido lugar en la estructura comercial y de servicios de la ciudad, y el flujo de peatones se ha incrementado. Lugares de reuniones y espacios públicos también están siendo remodelados para satisfacer las necesidades y las prácticas de los nuevos residentes y las poblaciones temporales procedentes de las zonas exteriores. 
En los últimos años, el uso de los espacios abiertos por la noche ha aumentado, por lo que durante todo el día el incremento de la población flotante ha favorecido la apertura de restaurantes, cafés y clubes nocturnos, y también ha visto unas mejoras introducidas en los ya existentes. Nuevas actividades - cafeterías, restaurantes de comida rápida, los comerciantes de vinos, galerías de arte, lugares de entretenimiento cultural, talleres de artesanía y tiendas de antigüedades - se han añadido a las "históricas". Las nuevas actividades a menudo están manejadas por los jóvenes, que han tenido el coraje de apostar en esta área central de la ciudad, y se concentran sobre todo en la comprensión de las tendencias actuales y las necesidades de los clientes. Para fomentar a los gentrificadores, muchas empresas comerciales han ampliado o hecho sus horarios de apertura más flexibles, de modo que la gente puede ir de compras durante las pausas de trabajo o en su camino a casa después del trabajo por la tarde. La nueva vitalidad comercial ha sido un factor determinante en la mejora de la seguridad y la calidad en el entorno urbano.

La principal fuerza impulsora detrás de la frecuentación cada vez más regular de las calles y de las plazas durante la tarde y la noche ha sido el movimiento en esta zona de los estudiantes de arquitectura que provienen de fuera de Génova durante la década de 1990. Con el traslado de la Facultad, los nuevos usuarios comenzaron a vivir en las calles, atrayendo durante el día a los compañeros de otras partes de la ciudad.

Poco después de su llegada, se puso en marcha un fenómeno innovador, rompiendo el molde, que vio la participación de muchos jóvenes de 20-35 años de edad, lo que estimuló la apertura de nuevos locales "de moda" para salir a cenar, disfrutando de la cultura del café y bailar toda la noche. La movida, el estilo de vida hedonista, se intensificó durante la segunda mitad de la década de 1990, con un número creciente de personas que se reunían por la noche en la Plaza delle Erbe, vía San Bernardo, Plaza Ferretto, salida Pollaiuoli, puerta Soprana, salida del Prione y, más recientemente, en la plaza Lavagna y en la plaza Lepre. Así se ha producido un rápido aumento en los negocios como restaurantes y varios centros de ocio, y han atraído a un público más amplio, aprovechando por el día la proximidad de los lugares de trabajo - las calles XX Settembre, Piccapietra y Carignano -, que además tienen una buena dotación de aparcamientos por la tarde y por la noche, ya sea con los coches aparcados de manera legal y a veces inapropiada. Los trabajadores visitan el centro histórico durante su hora de almuerzo: en este espacio-tiempo, mucha gente del centro de la ciudad llega al sector a comer en los típicos y pequeños restaurantes o en los bares del centro histórico, y llevar a cabo una serie de actividades complementarias como caminar y relajarse a lo largo de los principales ejes comerciales y de la renovada zona portuaria. El lunch break, la hora del almuerzo, es siempre un momento menos prolongado y más intenso del día laboral. En muchos casos, las funciones que tradicionalmente se desarrollaban después del trabajo, se trasladaron en este espaciotiempo, con repercusiones positivas evidentes en el tejido comercial. Por ejemplo, ir al gimnasio o de compras, conocer a la pareja, quedar con la propia red de amigos o algunos meeting de trabajo, hacer un pequeño recado, utilizar un servicio público, son algunas de las actividades que ahora se cumplen durante esta parte del día.

De hecho la población flotante constituida por los jóvenes estudiantes de arquitectura, diseñadores, artistas gráficos y fotógrafos han encontrado conveniente seguir viviendo cerca de la Facultad de Arquitectura, debido a un cierto tipo de fenómeno asociado con el efecto "creativo" atribuido a la vida en el centro histórico, pero también gracias a la oferta de espacio en proximidad de los principales servicios de la ciudad a un costo razonable. 

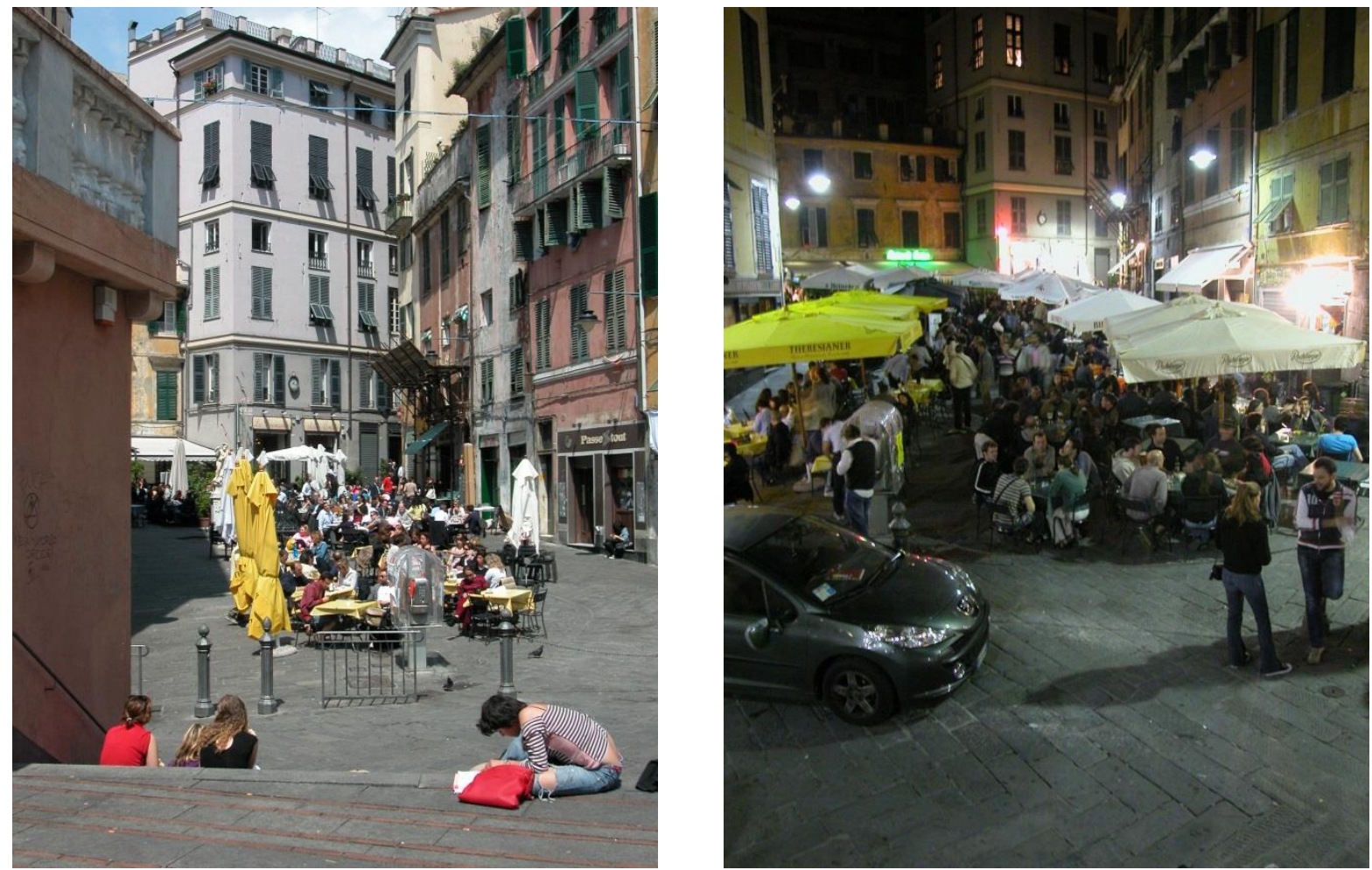

Fig. 4 y 5: a la izquierda la hora del almuerzo y a la derecha la movida por la noche en Plaza delle Erbe. Fuente: fotografías por Francesco Gastaldi.

Por último, el turismo genera otra población "flotante": en 2013, llegaron a los establecimientos turísticos del municipio de Génova 1.533 .098 personas, entre italianos y extranjeros, número que ha aumentado sostenidamente en el tiempo. Ese aumento está relacionado con el efecto del acuario en la zona de Porto Antico - con 1.034.750 de visitantes durante el 2013, un aumento del 7,6 por ciento respecto al 2012 (Ayuntamiento de Génova, 2014) - y con la oferta cultural renovada que pone a Génova dentro del circuito de las ciudades italianas de arte.

La zona de Plaza Caricamento se ha convertido en la "entrada principal" para la llegada de grupos de turistas en viajes organizados y también, en parte, para los turistas que llegan en coche, así como para los que vienen a la ciudad a través de la estación de tren de Plaza Principe. Los recorridos turísticos más populares de la ciudad se mueven a lo largo de Vía San Lorenzo, una ruta que recorre las atracciones más famosas de la ciudad: la Catedral, el Palacio Ducal y Puerta Soprano. Sin embargo, sigue habiendo prejuicios generalizados en contra de circular a pie, especialmente con respecto a los callejones menos frecuentados, pues aún se consideran peligrosos. Por otra parte, el mantenimiento de las actividades portuarias para los transbordadores y los cruceros dentro de la cuenca del Puerto Antiguo es reconocido como un factor estratégico y positivo que salvaguarda la imagen urbana y la identidad del barrio. Eso, a pesar de la presencia de la actividad turística, da a esta zona de la ciudad su propio dinamismo, para que la memoria de la historia económica genovés no se haya todavía perdido. 


\section{El éxito en la gestión de proyectos de regeneración urbana en Génova y los retos de la ciudad para el futuro}

La organización y gestión de proyectos vinculados a los grandes eventos - la Expo de Colón de 1992, la Cumbre del G8 de 2001 y Génova Capital de la Cultura de 2004 - han sido experiencias de especial interés por la capacidad de la autoridad pública, dentro de un marco de tiempo limitado, para ejecutar programas y procedimientos negociables entre los sectores público y privado, estrictamente relacionados con las sociedades privadas, empresas municipales y otros stakeholders importantes. Por otra parte, la experiencia ha fomentado el conocimiento, los recursos inconmensurables activados durante estos procesos, las redes de relaciones y unas capacidades y competencias de notable importancia. La administración pública, incluso ha sido capaz de descubrir y reactivar el know-how que parecía olvidado. Estos grandes eventos han actuado como un estímulo hacia el reconocimiento y la valorización de elementos de identidad, lo que provocó nuevas direcciones de desarrollo.

La reconversión del waterfront y las operaciones de mantenimiento en el centro histórico han llevado al cambio de la percepción de los residentes sobre su propia ciudad. La regeneración del watefront del Puerto Antiguo y la notable cantidad de lugares históricos recuperados, incluso también la reconversión de las grandes instalaciones industriales en desuso a través de la introducción de nuevos usos, se han traducido en un creciente sentido de pertenencia, reforzando los elementos identitarios a través del redescubrimiento de funciones colectivas y representativas a nivel metropolitano. Además, la imagen global de la ciudad se ve desde el exterior no sólo relacionado con el puerto y la industria, sino también como un nuevo elemento más vinculado al arte, la cultura, la belleza arquitectónica en una visión dinámica y propulsiva.

Este estudio confirma cómo el sistema de una serie de políticas públicas - de las cuales ninguna es suficiente para activar un mecanismo de regeneración por sí sola - puede crear una "masa crítica" capaz de estimular importantes precondiciones para desencadenar un proceso de regeneración urbana y de desarrollo local.

Sin duda, la re-ubicación de la Facultad de Arquitectura ha jugado un papel de liderazgo para la regeneración urbana del centro histórico, pero todas las otras transformaciones que se han sucedido en el tiempo han apoyado este fenómeno. La peatonalización de amplias zonas y la rehabilitación de espacios públicos y distintas áreas han desempeñado papeles igualmente importantes, como en la reapropiación material y simbólica y el redescubrimiento de una identidad urbana por parte de los residentes de la ciudad.

Una vez activados, los procesos de regeneración urbana han provocado un progresivo desarrollo de una nueva conciencia ciudadana en relación con el valor cultural del centro de Génova. Por supuesto, el gran aumento de los valores de la propiedad confirma los resultados obtenidos. Por lo tanto esta tendencia representa una medida significativa de los efectos inducidos por las transformaciones urbanas, y es un indicador útil sobre la eficacia de las intervenciones realizadas.

Para el futuro de Génova siguen abiertas algunas cuestiones relacionadas a la extensión de los efectos positivos de los grandes eventos sobre la regeneración urbana de la ciudad. En un contexto donde hay siempre menos recursos públicos, parece muy difícil terminar algunos importantes proyectos urbanos, entre los cuales destacan la realización del Parque Científico Tecnológico en el barrio Erzelli y la remodelación de Puente Parodi. Pues, ¿cómo capitalizar en el futuro el esfuerzo en la actuación para la mejora urbana que se ha logrado en el período 1992-2004? ¿Cómo se pueden difundir a otras partes de la ciudad los elementos virtuosos que se han producido? 
De hecho, con el evento de 2004 parece haber llegado el final de un ciclo que tuvo sus inicios a mediados de los años 80, cuando la región de Liguria, el municipio de Génova y el Consorcio Autónomo del Puerto firmaron el acuerdo que sancionó el abandono de los antiguos muelles con el fin de recuperarlos para usos recreativos y turísticos. Hoy la administración municipal, renovada en 2007 y más tarde en 2012, quiere, en términos de políticas y de intervenciones urbanas, crear una "discontinuidad" respeto a las iniciativas anteriormente descritas. Con un nuevo programa se plantea dar más atención al desarrollo urbano sostenible, la calidad de vida - sobre todo en referencia a los barrios de viviendas públicas -, los problemas entre la relación puerto-ciudad, el fomento de la investigación a través del nuevo centro tecnológico Erzelli. Pero hay la clara sensación de que la temporada de los "grandes eventos" es difícil de replicar en términos de eficacia de las intervenciones en el campo de las políticas y las transformaciones urbanas.

Hoy en día, en un período en que muchas zonas de la ciudad están esperando la implementación de diferentes proyectos urbanos13, se debería evaluar cuidadosamente la capacidad de estos proyectos para poner en marcha procesos de regeneración urbana o, por el contrario, si contribuirán a fomentar los fenómenos de segregación espacial de la población más débil. Entre los años Noventa y principios del siglo XXI una gran cantidad de iniciativas y también de muchos recursos económicos públicos se dedicaron a la parte central de la ciudad waterfront y centro histórico -, pero se ha invertido muy poco en otras áreas, al oeste y al este de la ciudad, que aparecen las más marginadas y menos competitivas de Génova.

El futuro de estas zonas también dependerá de algunas nuevas oportunidades y ocasiones, por las cuales es difícil de predecir el resultado en el momento actual. Las nuevas intervenciones de regeneración urbana serán fundamentales en términos de inclusión social, atracción de nuevas poblaciones y procesos de desplazamiento y se deberá tener en cuenta el correspondiente impacto en los valores de propiedad, de la calidad de vida y de los espacios públicos. Además muy importante será la tarea de las acciones de las instituciones públicas que pueden actuar como un estímulo, solicitud y coordinación de las acciones de los actores públicos y privados.

\section{Conclusiones}

Teniendo en cuenta la amplia gama de literatura sobre el tema, (Gaeta, 2006; Smith N., 1997 y 2001; Zukin, 1982, 1987 y 1995) y a la luz del análisis expuesto se confirma que en el centro histórico de Génova la gentrificación se ha desencadenado como un proceso "suave" de cambio social relacionado con las operaciones de transformación urbana, y no haya llevado a la expulsión masiva de la clase débil de las zonas interesadas por la implementación de las políticas de regeneración urbana, como se ha verificado en otras ciudades del mundo. De hecho los autores exprimen un juicio tendencialmente positivo de la gentrificación que se ha desarrollado en el centro histórico de Génova, porque ha contribuido a la mejora del barrio, fomentando un proceso de cambio en la composición de sus habitantes - más jóvenes, italianos y con un más alto nivel de estudio -, y de la población flotante - estudiantes no residentes, turistas, trabajadores. El cambio en la población, sin embargo, implicó el desplazamiento de algunas componentes de los habitantes, sobre todo de una parte de la población extranjera que inmigró en el centro histórico en los años noventa. Por lo que merece a los extranjeros que aún viven en este barrio, se verificó la tendencia a concentrarse en ciertas áreas del centro histórico mientras otros decidieron desplazarse en otros barrios que se caracterizan por una fuerte degradación del entorno urbano. Por otra parte el aumento de

13 Entre los cuales destacan la futura actuación del proyecto urbano por Renzo Piano llamado Blue Print, sobre la parte de levante de la ciudad (Minella, 2015), el nuevo centro tecnológico Erzelli y la regeneración del área del Puente Parodi. 
mixtura social que algunos estudiosos han denominado "gentrificación furtiva" (Bridge, Butler y Lees, 2013), tuvo como consecuencia el crecimiento de los valores por metro cuadrado de edificios residenciales. En vez como elementos positivos de las transformaciones se incluyen el aumento de la seguridad urbana y de la calidad de la vida, y también la restauración de las fachadas de los edificios. Otros efectos que se detectaron fueron el incremento de empresarios culturales - y el papel activo que han desempeñado en la modificación y mejora del tejido comercial en el centro histórico de Génova - y la protección de la memoria del pasado auténtico y multicultural del centro histórico, defendida por los gentrificadores más atentos a los ideales de conservación y por el community-making local.

Además se demuestra que la gentrificación de Génova se ha detonado por los siguientes fenómenos: el cambio de la composición social de los barrios; la restauración de edificios y la localización central (Bagnasco, 1990; Caccamo, 1994; Minca, 2001), aunque no haya mejorado la calidad de vida de la población residente más vulnerable. Los procesos de intervención urbana han atraído una nueva población con mejores recursos, desplazando a los extranjeros hacia otros barrios de la ciudad. Estos cuatro elementos se han producido en Génova y, además, un papel fundamental también ha sido interpretado por otras componentes. En específico se incluye la identidad cultural e histórica de la zona; la ausencia de conflicto relevante o permanente entre los diferentes tipos de residentes afectados por la transformación social; la recalificación de los edificios, que ha sido generalizada en algunas zonas; la apertura nuevos restaurantes "de moda", pubs, cafeterías y discotecas; la evolución general del tejido comercial como una nueva función por los nuevos usuarios que se han instalado en la ciudad; y una demanda recreativo-cultural también sensible al componente artístico de la oferta comercial. Los frecuentes conflictos y protestas de los residentes por el ruido de la vida nocturna se trasladaron a las sedes municipales en 2008: los vecinos pedían limitar las actividades de estos negocios a la una de la noche durante la semana, y hasta las dos de la madrugada los viernes y sábados por la noche.

Finalmente, se necesita averiguar si el fenómeno de gentrificación será capaz de extenderse por autopropagación por un período de tiempo prolongado una vez que la fase de reconstrucción y mantenimiento urbano conectado con los grandes eventos - y sus efectos inmediatos - hayan terminado, incluso cuando no habrán más fondos públicos disponibles. Puede verificarse la hipótesis de que, en el futuro, la ciudad no será capaz de beneficiarse de los recursos públicos de la forma excepcional que ha podido realizarse durante los últimos veinte años. En consecuencia, una gran parte del éxito de Génova depende de la capacidad de la ciudad y de su sistema urbano para integrarse en nuevas redes internacionales y competitivas.

\section{Referencias}

AMBROSINI Maurizio, TORRE Andrea, Settimo rapporto sull'immigrazione a Genova, Génova, Il Melangolo, 200 págs, ISBN: 978-88-7018-849-3

ANNUNZIATA, Sandra, "Oltre la gentrification", en LANZANI, Arturo; MORONI, Stefano (eds.), Città e azione pubblica. Riformismo al plurale, Roma, Carocci Editore, 2007, pp. 79-84. ISBN: 978-88-43-042241

ARVATI, Paolo, "Chiedevamo braccia, sono arrivati uomini", en La Repubblica, edizione Genova, 28 de julio de 2004, en web:

http://ricerca.repubblica.it/repubblica/archivio/repubblica/2004/07/28/chiedevamo-braccia-sono-arrivatiuomini.html 
ANNUNZIATA, Sandra, "Gentrification and Public Policies in Italy", en CALAFATI, Antonio (ed.), The Changing Italian Cities: Emerging Imbalances and Conflicts, L'Aquila, GSSI Urban Studies - Working Papers 6, 2014, pp. 23-34. ISBN: 978-88-98974-00-9

ATKINSON Rowland (2003), "Introduction: misunderstood saviour or vengeful wrecker? The many meanings and problems of gentrification", en Urban Studies, 12 (40) 2003, pp. 2343-2350. ISSN: 00420980

ATKINSON, Rowland; BRIDGE, Gary (eds.), Gentrification in a global contest. The new urban colonialism, Londres, Routledge, 2005, 300 págs., ISBN: 041-53-2951-5

GASTALDI, Francesco, CAMERIN, Federico, "Effetti ed eredità dei grandi eventi: Italia e Spagna a confronto", en AREL, 2, 2015, pp. 39-45. ISSN: 2039-0181

AYUNTAMENTO DE GÉNOVA, Annuario statistico edizione 2014, 2014, en web: http://statistica.comune.genova.it/pubblicazioni/download/annuario/Annuario\%202014/ANNUARIO\%2020 14.pdf

AYUNTAMENTO DE GÉNOVA, Notiziario statistico 2015, en web:

http://statistica.comune.genova.it/pubblicazioni/download/not_stat/not_1_2015/notiziario_1_2015.pdf

BAGNASCO, Arnaldo (ed.), La città dopo Ford, Turin, Bollati Boringhieri, 1990, 160 págs., ISBN: 978-883390521-1

BARBAGLI, Marzio; PISATI, Maurizio, Dentro e fuori le mura. Città e gruppi sociali dal 1400 ad oggi. Bolonia, Il Mulino, 2012, pp. 484. ISBN: 978-88-15-24048-4

BOBBIO, Roberto (2003), "Nuove cittadinanze a Genova", en Urbanistica Informazioni, 188, pp. 9-11. ISSN: 0392-5005

BOBBIO, Luigi; GUALA, Chito (eds.), Olimpiadi e grandi eventi, Roma, Carocci Editore, 2002, 232 págs., ISBN: 978-88-43-02247-2

BONDONIO, Piervincenzo; GUALA, Chito (eds.), Gran Torino. Eventi, turismo, cultura, economia, Roma, Carocci Editore, 2012, 184 págs., ISBN: 978-88-43-06675-9

BOVONE, Laura (ed.), Un quartiere alla moda. Immagini e resoconti del Ticinese a Milano, Milán, FrancoAngeli, 2002, 298 págs., ISBN: 978-88-46-41293-5

BOVONE, Laura; MAZZETTE, Antonietta; ROVATI, Giancarlo (eds.), Effervescenze urbane. Quartieri creativi a Milano, Genova e Sassari, Milán, FrancoAngeli, 2005, 208 págs., ISBN: 978-88-46-46613-6

BRIATA, Paola, Spazio urbano e immigrazione in Italia. Esperienze di pianificazione in una prospettiva europea, Milán, FrancoAngeli, 2014, 128 págs., ISBN 9788820462628

BRIDGE, Gary, BUTLER, Tim, Lees, Loretta (eds.), Mixed communities: gentrification by stealth?, Londres, Policy Press, 2013, 372 págs., ISBN: 978-1847424921

BRENNER, Neil; PATCH, Jason, "Gentrification", en RITZER, George (ed.), Encyclopedia of Sociology, Oxford y Boston, Blackwell, 2007, pp. 1917-1920. ISBN: 978-1-4833-0294-2

BRUTTOMESSO, Rinio (ed.), Water and Industrial Heritage, Venecia, Marsilio Editori, 1999, 175 págs., ISBN 88-317-7231-7

CACCAMO, Rita, Solitudine: ricerca e fuga. Single urbani tra pionierismo e sopravvivenza, Milán, Anabasi, 1994, 234 págs., ISBN: 88-417-5014-6

CAMERON, Stuart, Housing, Gentrification and Urban Regeneration Policies, en Urban Studies 29 (1), 1992, pp 3-14. ISSN: 0042-0980 
CASTRILLO, María; MATESANZ, Ángela; SEVILLA, Álvaro; DOMINGO SÁNCHEZ, Fuentes, "¿Regeneración urbana? Deconstrucción y reconstrucción de un concepto incuestionado", en Papeles de relaciones ecosociales y cambio global, 126, 2014, pp. 129-139. ISSN: 1888-0576

CHOAY Françoise, Alegoría del patrimonio, Barcelona, Gustavo Gili, 264 págs., 2015. ISBN: 9788425222368

COUCH, Cris; FRASER, Charles; PERCY, Susan (eds.), Urban Regeneration in Europe. Oxford, Blackwell Publishing Company, 2003, 256 págs., ISBN 0-632-05841-2

DELGADO, Manuel (2007). La ciudad mentirosa. Fraude y miseria del "modelo Barcelona". Madrid, Los libros de la Catarata, 2007, 256 págs., ISBN: 978-84-8319-320-4

DI VITA, Stefano, Milano Expo 2015. Un'occasione di sviluppo sostenibile, Milán, FrancoAngeli, 2010, 320 págs., ISBN: 978-88-5682452-0

DIAPPI, Lidia (ed.), Rigenerazione urbana e ricambio sociale. Gentrification in atto nei quartieri storici italiani, Milán, FrancoAngeli, 2009, 192 págs., ISBN: 9788856802665

ERMINIO, Deborah, "Il profilo socio-demografico dei migranti", en AMBROSINI Maurizio; TORRE, Andrea; QUEIROLO PALMAS, Luca (eds.), Terzo rapporto sull'immigrazione a Genova, Génova, Fratelli Frilli Editore, 2006, pp. 31-111. ISBN: 978-8875632212

FAGENCE, Michael, "City Waterfront Redevelopment for Leisure, Recreation, and Tourism: Some Common Themes", en CRAIG-SMITH, Stephen; FAGENCE, Michael. (eds.), Recreation and Tourism as a Catalyst for Urban Waterfront Redevelopment, Praeger, Wesport Connecticut, 1995, pp. 135-156, ISBN: 0-27594550-2

FLORIDA, Richard, The rise of the creative class, Nueva York, Basic Books, 2002, 404 págs., ISBN: 9781491576762

GAETA, Luca, "Realtà e ideologia della gentrification. Un sommario della letteratura", en Impresa, mercato e lealtà territoriale, Pisa, XXVII Conferenza Italiana di Scienze Regionali, 12-14 Octubre 2006, 18 págs., (CD-Rom)

GAMBINO, Roberto; MONDINI, Giulio; PEANO, Attilia (Eds.) (2005). Le olimpiadi per il territorio, Milán, Edizioni Il Sole 24 Ore, 2005, 167 págs., ISBN: 978-88-3245736-0

GUALA, Chito, "Tra ricerca e partecipazione. I comitati del centro storico di Genova", en MARTINELLI, Franco, GUIDICINI, Paolo (eds.), Le nuove forme di urbanità, Milán, FrancoAngeli, 1993, pp. 247-258. ISBN: $978-88-20-48292-3$

GUALA, Chito, Mega Eventi. Modelli e storie di rigenerazione urbana, Roma, Carocci Editore, 2007, 184 págs., ISBN: 978-88-43-04298-2

GUALA, Chito, "Torino, i XX Giochi Olimpici e la stagione dei mega eventi", en Territorio, 48, 2009, pp. 103-109. ISSN 1825-8689

HARVEY, David, The Urbanisation of Capital, Londres, Blackwell, 1985. 239 págs., ISBN: 0-631-14068-9

HELMS, Andrew. "Understanding gentrification: an empirical analysis of the determinants of urban housing renovation" en Journal of Urban Economics, 54, 2003, pp. 474-498. ISSN: 0094-1190

INSTITUTO UNIVERSITARIO DE URBANÍSTICA DE LA UNIVERSIDAD DE VALLADOLID, Regeneración urbana integrada en Europa. Documento de síntesis, 2010, en web:

http://www.upv.es/contenidos/CAMUNISO/info/U0669348.pdf

LAGOMARSINO, Francesca, "Dall'Ecuador a Genova: un modello migratorio in evoluzione", en AMBROSINI M., ERMINIO D., RAVECCA A. (eds.), Primo rapporto sull'immigrazione a Genova, Génova, Fratelli Frilli Editore, 2004, pp. 263-302. ISBN: 9788875630645 
LEES, Loretta, "Gentrification and Social Mixing: Towards an Inclusive Urban renaissance?", en Urban Studies, 45 (12), 2008, pp. 2449-2470. ISSN: 0042-0980

LEONE, Marco, La leggenda dei vicoli. Analisi documentaria di una rappresentazione sociale del centro antico di Genova, Milán, FrancoAngeli, 2010, 176 págs., ISBN: 978-88-56-82501-5

LOGAN, John; MOLOTCH, Harvey, Urban fortunes: the political economy of place, Los Angeles, University of California Press, 1987, 383 págs., ISBN: 0-520-06341-4

MANZO, Lidia, "On People In Changing Neighborhoods. Gentrification and Social Mix: Boundaries and Resistance. A comparative ethnography of two historic neighborhoods in Milan and Brooklyn", en CIDADES, Comunidades e Territórios, 24, 2012, pp. 1-29. ISSN: 2182-3030

MARTINOTTI, Guido, Metropoli. La nuova morfologia sociale della città, Bolonia, Il Mulino, 1993, 244 págs., ISBN: 978-88-15-03697-1

MAZZOLENI, Chiara, La costruzione dello spazio urbano: I'esperienza di Barcellona. Milán: Franco Angeli, 2009, 192 págs., ISBN: 978-88-56-80489-8

MINCA, C. (2001), "Lo spazio gentrificato come 'testo' urbano", en BONORA, Paola (ed.), Comcities. Geografie della comunicazione, Bolonia, Baskerville, 2001, pp. 175-189. ISBN: 978-88-8000-308-3

NEL·LO, Oriol, "The challenges of urban renewal. Ten lessons from catalan experience", en Análise Social, Vol. 45 (197), 2010, pp. 685-715. ISSN 0003-2573

NUVOLATI, Gianpaolo (2002), Popolazioni in movimento, città in trasformazione, Bolonia, Il Mulino, 296 págs., ISBN: 978-88-15-23254-0

OSSERVATORIO MERCATO IMMOBILIARE E SERVIZI ESTIMATIVI, Nota trimestrale. Andamento del mercato immobiliare nel IV trimestre 2014 e sintesi annua, 34 págs., en el web:

http://www.agenziaentrate.gov.it/wps/file/Nsilib/Nsi/Documentazione/omi/Pubblicazioni/Note+trimestrali/ Nota+trimestrale+andamento+mercato+immobiliare+IV+trim_2014/OMI_Nota_IV_trimestre_2014.pdf

PETRILLO, Agostino, "Genova e i migranti. Storia recente e prospettive future", en RUGAFIORI Paride (ed.), Genova del Saper Fare. Lavoro, imprese, tecnologie, Milán, Skirà Editore, 2004, pp. 171-178. ISBN: 888491945

PICCOLOMINI Michele, "The gentrification. Processi e fenomenologie dell'urbanizzazione avanzata', en Sociologia e ricerca sociale, Vol. 40, 1993, pp. 49-75. ISSN: 0392-4939

QUEIROLO PALMAS Luca, TORRE Andrea (ed.), Il fantasma delle bande. Genova e i latinos, Génova, Fratelli Frilli Editore, 2005, 336 págs., ISBN: 978-8875630652

ROBERTS Peter, SYKES Sir Hugh, Urban Regeneration. A handbook, Londres, SAGE Publications, 2000, 340 págs., ISBN: 978-0761967163

ROCCA, Giuseppe, "La presenza straniera in Liguria e nell'area urbana genovese", en BRUSA Carlo (ed.), Immigrazione e multicultura nell'Italia di oggi, Milán, FrancoAngeli, 1997, pp. 235-254. ISBN:

9788846402462

ROCHE, Maurice, Mega-events and modernity: Olympics and expos in the growth of global culture, Londres, Routledge, 2000, 304 págs., ISBN: 0415157129

SEASSARO, Loredana, "Tra porto e città: logiche aziendali, neoutilitarismo e contrattualismo", en Urbanistica Informazioni, Vol. 178, 2001, pp. 45-46. ISSN 0392-5005

SEGRE, Anna; SCAMUZZI, Sergio (eds.), Aspettando le olimpiadi, Roma, Carocci Editore, 2004, 224 págs., ISBN: 978-88-43-02978-5

SEMI, Giovanni, "Il quartiere che (si) distingue. Un caso di gentrification a Torino", en Studi culturali, Vol. 1, 2004, pp. 83-107. ISSN: 1824-369X 


\section{URBANISMO}

SEMI, Giovanni, Gentrification. Tutte le città come Disneyland?, Bolonia, Il Mulino, 2015, 150 págs., ISBN: 9788815258038

SCHUBERT Dirk, "Transformación de zonas portuarias y costeras en desusoexperiencias, posibilidades y problemas", en Ciudades, 8, 2004, pp. 15-36. ISSN 1133-6579

SLATER, Tom, "The Eviction of Critical perspectives from Gentrification Research",en International Journal of Urban and Regional Research, 30 (4), pp. 737-57, 2006. ISSN: 1468-2427

SMITH, Darren, "Studentification: the gentrification factory?", en ATKINSON, Rowland; BRIDGE, Gary (eds.), Gentrification in a global context: the new urban colonialism. Housing and Society Series, Londres, Routledge, 2005, pp. 72-89. ISBN: 0415329515

SMITH, Neil, "Gentrification and the rent gap", en Annals of the Association of American Geographers, Vol. 77, No. 3, 1987, pp. 462-465. ISSN: 1467-8306

SMITH, Neil, The new urban frontier: Gentrification and the revanchist city, Londres, Routledge, 1996, 288 págs., ISBN: 978-04-15-13255-8

SMITH, Neil, "Rescaling politics geography, globalism and new urbanism", en MINCA, Claudio (ed.), Postmodern geography: Theory and praxis, Oxford, Blackwell, 2001, pp. 147-165. ISBN: 978-0-63122559-1

TORTI, Maria Teresa (ed.), Stranieri in Liguria. Ricerca condotta dall'TLRES, Génova, Marietti, 1992, 184 págs., ISBN: 8821199258

VITELLIO, Ilaria, Regimi urbani e grandi eventi, Milán, FrancoAngeli, 2009, 224 págs., ISBN: 978-88-56$81555-9$

ZUKIN, Sharon, Loft living: Culture and capital in urban change, Baltimore, MD, Johns Hopkins University Press, 1982, 224 págs., ISBN: 978-08-01-82694-8

ZUKIN, Sharon, "Gentrification: Culture and Capital in the Urban Core", en Annual Review of Sociology, Vol. 13, 1987, pp. 129-147. ISBN: 9780824322137

ZUKIN, Sharon, The cultures of the cities, Oxford, Blackwell, 1995, 338 págs., ISBN: 978-1-55786-437-6 